\title{
TECHNOLOGICAL AND THEORETICAL APPLICATION OF FINITE ELEMENT MODELING OF DEEP DRAWING
}

\author{
Ádám BERTÓK1ㄴ, Viktor GONDA², Károly SZÉLL ${ }^{3}$ \\ ${ }^{1,2}$ Óbuda University, Donát Bánki Faculty of Mechanical and Safety Engineering, Budapest, Hungary \\ 1 adambertok94@gmail.com \\ ${ }^{2}$ gonda.viktor@bgk.uni-obuda.hu \\ ${ }_{3}^{3}$ Óbuda University, Alba Regia Mechanical Faculty, Székesfehérvár, Hungary, pethod@almos.uni-pannon.hu
}

\begin{abstract}
For metal forming problems, even for a simple forming technology, finite element analysis can provide a solution for calculating deformations, determining stress and strain distributions. The aim of this study is to create a parametric finite element model for deep drawing technology, by which technological optimization as well as theoretical problems can be solved. By performing parameter studies, numerous cases can be analyzed.
\end{abstract}

Keywords: metal forming, finite element modeling, deep drawing.

\section{Introduction}

Deep drawing is one of the most widely used sheet forming operations in which a cup can be produced from the flat blank. When analysing deep drawing technology, finite element modelling provides help for analysis of deformations and stresses and for deriving technological parameters. Our goal was to create a finite element parametric base model for deep drawing technology that can be easily employed for technological and theoretical problems. In the present paper, we show the structure of the axial symmetric finite element model and then the use of the model for a technology design example and for the theoretical cup draw limit estimation.

\section{The structure of the finite element model}

The base model was constructed for simulation of deep drawing with a punch, a die and a blank without a blank holder, as shown in Figure 1. Optimal values for the fillet radii of the punch and the die were determined by the recommendations in the design guidelines [1].
MSC MARC Mentat were employed for the finite element modelling. In order to perform the finite element simulation, we first had to create

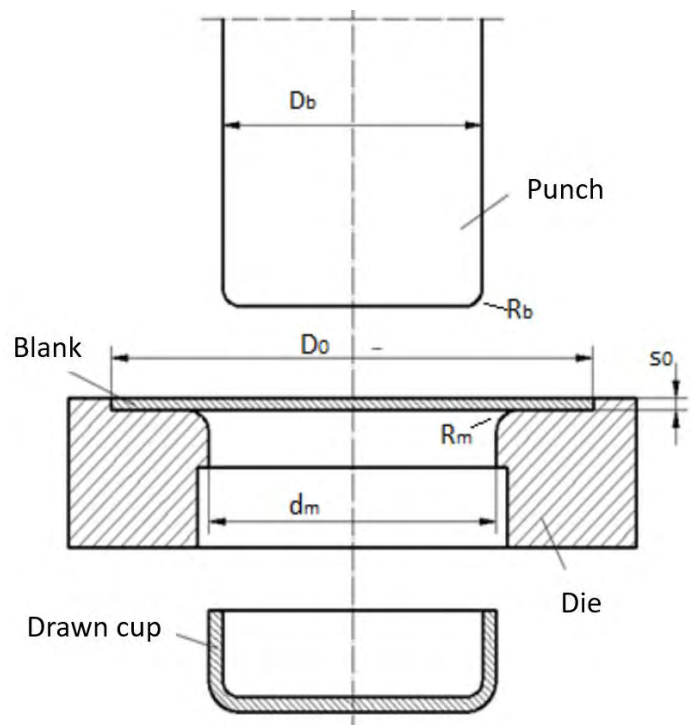

Figure 1. Schematics of the modelled setup of deep drawing 
the geometry of the model to be tested. Utilizing the axisymmetry, we created a planar model (Figure 2.). The basic model was built parametrically to facilitate future ease of use.

The material model for the blank was considered as elastic-plastic hardening. The material parameters for DC03 grade steel of the blank were fed in the model in a tabular manner. In the axisymmetric model, the material was considered as isotropic. Geometrical features for the tools were modelled as rigid. For the moving tool element, the punch, time function of tool movement was assigned as a linear function in tabular form.

In parallel with creating the model, we created a so-called procedure file so that the base program could be more easily modified for specific tasks. This made it easy to modify the geometry and accelerated the evaluation of the results.

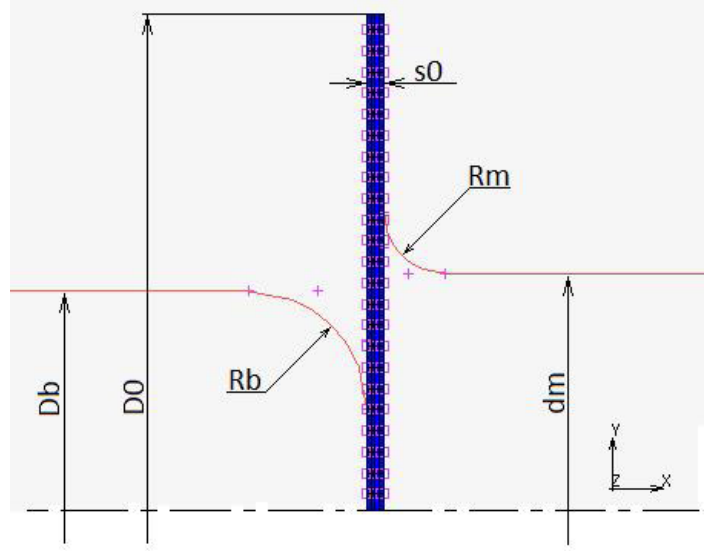

Figure 2. The structure of the finite element model

\section{Application of the model}

\subsection{Design of Technology}

Initially, the blank diameter was $\mathrm{D}_{0}=82.5 \mathrm{~mm}$, and the diameter of the punch was modelled with $\mathrm{D}_{\mathrm{b}}=27 \mathrm{~mm}$. When running the calculation, it is apparent from the results that the perimeter cannot be fully retracted by this geometry, the element near the bottom of the cup's body extends, then begins to thin, the bottom of the cup may tear (Figure 3.). As drawing of the flange began, its material hardened, the force required to draw it increased so that it could no longer be transferred to the bottom, if the flange is blocked. In reality, the bottom would tear, but there is no damage criteria in the model, therefore unrealistic thinning of the rim is observed.

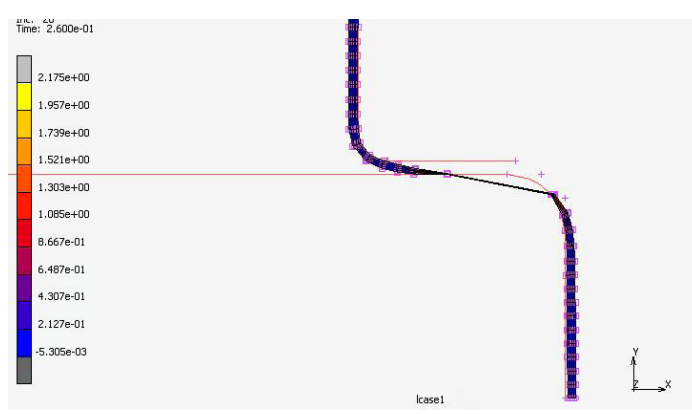

Figure 3. The case of the bottom breaking

This case can be considered as the theoretical drawability limit and should be distinguished from the bottom tear which may awaken during drawing when the stress reaches the tensile strength value in the wall.

Subsequently, the internal diameter of the cup was increased to $D_{b}=49 \mathrm{~mm}$ to increase the diameter of the die, but we did not change the rest of the geometry data: clearance, and fillet radii.

When the simulation is executed, the flange is drawn in. Here we calculate the inverse drawing ratio, $m$, (the ratio of the punch diameter and the blank diameter):

$$
m=\frac{D_{b}}{D_{0}}=\frac{49}{82.5}=0.59
$$

Subsequently, various technological parameters were analysed, these included the characteristics of the drawing force. The force-displacement diagram was plotted for the punch (Figure 4.). The maximum drawing force read out from the diagram was:

$$
F_{\max }=25570 \mathrm{~N}
$$

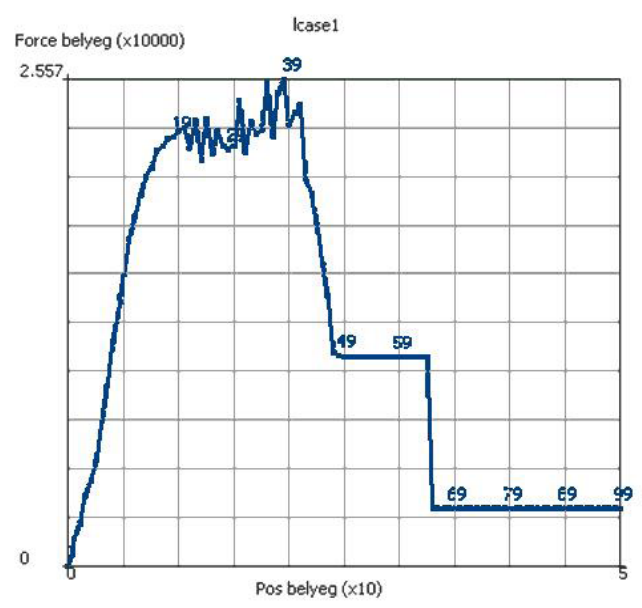

Figure 4. The force characteristics of deep drawing $\left(D_{0}=82,5 \mathrm{~mm} ; D_{b}=49 \mathrm{~mm}\right)$ 
The critical force $\left(F_{k r i}\right)$ belonging to the bottom break may be estimated by the following formula:

$$
F_{k r i t}=A \cdot R_{m}=25658 \mathrm{~N}
$$

where:

- $A$ : the cross-sectional area of the cup in $\mathrm{mm}^{2}$,

- $R_{m}$ : tensile strength, $330 \mathrm{MPa}$.

Because:

$$
F_{\text {max }}<F_{\text {krit }}
$$

with this parameter combination, drawing can be executed.

We have presented a possible solution to technological design with the virtual tests carried out.

\subsection{Cup drawing test}

The cup drawing test is a technological test of deep drawing. The test is described in MSZ 5731 [2]. The examination can actually be regarded as an experimental drawing. The schematic of the cup drawing test is shown in Figure 5.

In the course of the test, deep drawing is performed on a particular sheet material with different blank diameters, the aim being to determine the maximum blank diameter that can be drawn in without damage. From the test, the inverse drawing limit ratio can be calculated.

By modelling the test, the theoretical draw ratio can be estimated for a given sheet material with a given thickness and blank diameter.

The modelling of the test was performed on a given grade of two different thicknesses: $0.5 \mathrm{~mm}$ and $3 \mathrm{~mm}$. Our preliminary expectation is that the thick sheet has a better drawability and therefore a larger blank diameter can be drawn in.

The results of the simulation of the cup draw test for the two sheet thicknesses are shown in Table 1. On the basis of the results, contrary to expectations, the thinner plate proved to be more drawable, as there is a larger drawable blank diameter. This is due to the large thickening of the flange in the case of the $3 \mathrm{~mm}$ sheet thickness. In this case, the wall thickness of the cup is so large that the material fills the clearance and the

Table 1. The results of the simulation of the cup draw test for thin and thick blank sheets

\begin{tabular}{|l|c|c|}
\hline & $\begin{array}{c}\text { Drawable } \\
\text { diameter }\end{array}$ & $\begin{array}{c}\text { Inverse draw ratio } \\
\text { (m) }\end{array}$ \\
\hline Thin sheet & $68 \mathrm{~mm}$ & 0.49 \\
\hline Thick sheet & $66 \mathrm{~mm}$ & 0.5 \\
\hline
\end{tabular}

flange is ironed. This was observed in the simulations of the $3 \mathrm{~mm}$ sheet drawing (Figure 6.). In addition, it is worth examining the force acting on the punch. The peak appearing on the force characteristic demonstrates the additional force required for ironing (Figure 7.).

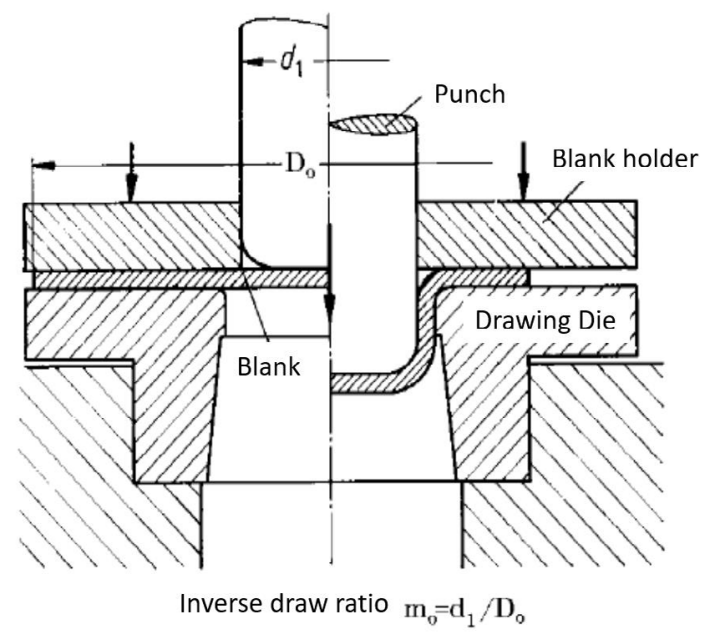

Figure 5. A schematic of the cup drawing test

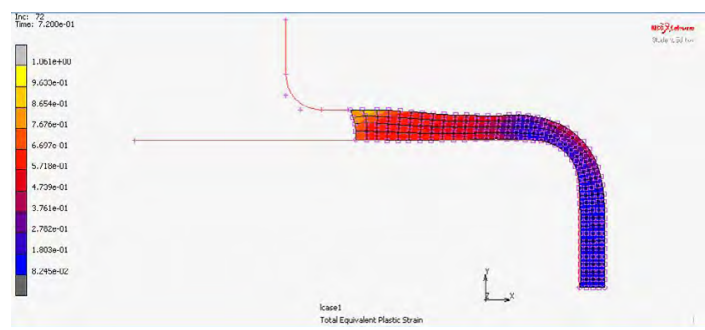

Figure 6. Flange thickening during drawing Force belyeg (x1e5)

3

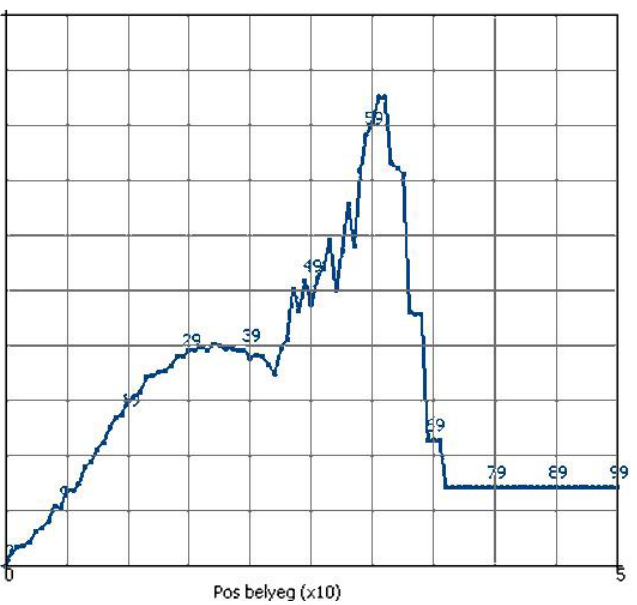

Figure 7. Force-displacement characteristics for deep drawing with ironing ( $3 \mathrm{~mm}$ thick blank) 


\section{Acknowledgments}

The authors express their thanks to the grants of the Ministry of Human Resources ÚNKP-17-I-OE-779/15 as well as the EFOP-3.6.1-16-2016-00010 for the support.

\section{References}

[1] Horváth L.: Mélyhúzás technológia tervezése. Oktatási segédlet. Óbuda University, 2009.

[2] Sárvári J.: Képlékeny hidegalakítás. Nemzeti Tankönyvkiadó. 